\title{
Important risk factors and attributable risk of vertebral fractures in the population-based Tromsø study
}

Svanhild Waterloo ${ }^{1 *}$, Tuan Nguyen², Luai A Ahmed ${ }^{3}$, Jacqueline R Center ${ }^{2,4}$, Bente Morseth ${ }^{1}$, Nguyen D Nguyen², John A Eisman ${ }^{2,4}$, Anne J Søgaard ${ }^{5}$ and Nina Emaus ${ }^{3}$

\begin{abstract}
Background: Vertebral fractures, the most common type of osteoporotic fractures, are associated with increased risk of subsequent fracture, morbidity, and mortality. The aim of this study was to examine the contribution of important risk factors to the variability in vertebral fracture risk.

Methods: Vertebral fracture was ascertained by VFA method (DXA, GE Lunar Prodigy) in 2887 men and women, aged between 38 and 87 years, in the population-based Tromsø Study 2007/2008. Bone mineral density (BMD; $\mathrm{g} / \mathrm{cm}^{2}$ ) at the hip was measured by DXA. Lifestyle information was collected by questionnaires. Multivariable logistic regression model, with anthropometric and lifestyle factors included, was used to assess the association between each or combined risk factors and vertebral fracture risk. Population attributable risk was estimated for combined risk factors in the final multivariable model.

Results: In both sexes, age (odds ratio [OR] per 5 year increase: 1.32; 95\% Cl 1.19-1.45 in women and 1.21; 95\% $\mathrm{Cl} 1.10-1.33$ in men) and BMD (OR per SD decrease: 1.60; 95\% Cl 1.34-1.90 in women and 1.40; 95\% Cl 1.18-1.67 in men) were independent risk factors for vertebral fracture. At BMD levels higher than $0.85 \mathrm{~g} / \mathrm{cm}^{2}$, men had a greater risk of fracture than women (OR 1.52; 95\% Cl 1.14-2.04), after adjusting for age. In women and men, respectively, approximately $46 \%$ and $33 \%$ of vertebral fracture risk was attributable to advancing age (more than 70 years) and low BMD (less than $0.85 \mathrm{~g} / \mathrm{cm}^{2}$ ), with the latter having a greater effect than the former.

Conclusions: These data confirm that age and BMD are major risk factors for vertebral fracture risk. However, in both sexes the two factors accounted for less than half of fracture risk. The identification of individuals with vertebral fracture is still a challenge.
\end{abstract}

Keywords: Morphometry, Vertebral fractures, Risk factors, Population based study, Population attributable risk (par)

\section{Background}

Fragility fracture is highly prevalent in the general population, and is increasingly becoming a public health concern $[1,2]$. From the age of 60 , the lifetime risk of any fracture in Norway is $63 \%$ in women and $34 \%$ in men [3]. Although hip fracture is the most serious consequence of osteoporosis [4], other osteoporotic fractures are also associated with important health issues as pain [5], loss of function [6], and increased risk of new

\footnotetext{
* Correspondence: svanhild.h.waterloo@uit.no

${ }^{1}$ Department of Community Medicine, Faculty of Health Sciences, University of Tromsø, Tromsø 9037, Norway

Full list of author information is available at the end of the article
}

fractures [7]. Some studies have suggested that clinical vertebral fractures are associated with increased risk of subsequent vertebral fractures [8-10], non-vertebral fractures [11-14], and mortality [15]. Vertebral fracture is often underestimated due largely to the problem of under-diagnosis. Indeed, only one in three vertebral fractures is clinically diagnosed [5,16], and the majority is either undetected or incidentally detected through radiographs. Recent development in dual x-ray absorptiometry (DXA) technology has allowed a population based assessment of vertebral fracture to be carried out by common DXA densitometers [17]. The vertebral fracture assessment (VFA) method has been used in many

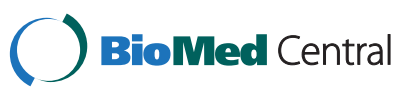


population settings, and its sensitivity and specificity are comparable to spinal radiographs in the ability to diagnose grade 2 and 3 (moderate and severe) vertebral fracture $[13,17]$. These developments provide opportunities for studies of vertebral fracture risk.

Norway is among the countries in the world with the highest incidence of fragility fractures, including hip [18] and forearm [19]. According to the FRAX risk calculator, age, sex, body mass index, previous fracture, parental hip fracture history, alcohol, tobacco, arthritis, and use of glucocorticoids constitute important risk factors for osteoporotic fractures [20]. Studies on vertebral fractures indicate that among these, age, bone mineral density (BMD), and previous fractures are the most significant risk factors [21,22]. Data recently reported from the Tromsø Study in Norway indicate that the prevalence of vertebral fractures do not differ between women and men [23]. The aim of the present study was therefore to address the important risk factors for vertebral fractures in a Norwegian population, and to estimate the percentage of fracture cases that can be explained by these risk factors.

\section{Methods}

\section{Study population}

The present study is part of the on-going Tromsø Study (www.tromsostudy.com). Details of study design have been described elsewhere [24]. Briefly, the study is a longitudinal, population-based investigation in Tromsø (Norway), a city of nearly 70000 inhabitants. The study comprises six repeated surveys from its start in 1974 (Tromsø I) through 2007/08 (Tromsø VI) [24]. Only men were invited to the first survey, but from Tromsø II 1979/80 both women and men have been included. The participation rate have ranged from $65 \%$ to $77 \%$ [24]. Each survey has been conducted in two phases, with the most basic examination in phase 1 (height, weight, blood pressure, blood samples, and questionnaires) and more extensive examinations for a random sub-sample of the cohort in phase 2, depending on available financial resources. The Tromsø Study, including this study, has been approved by the Norwegian Data Inspectorate and the Regional Committees for Medical and Health Research Ethics (Rec North). All participants signed a written informed consent.

The present study is based on data from Tromsø VI, details described elsewhere [23]. In short, 9625 men and 10137 women were invited, and 6054 men (62.9\%) and 6930 women $(68.4 \%)$ attended phase 1 of the survey. Among those, a total of 11484 subjects were invited for phase 2, and 3141 men (61.5\%) and 4166 women $(65.3 \%)$ attended. Persons with valid BMD measuremenst from Tromsø V in 2001/2002 were invited for BMD measurements of the hip, i.e. a dual femur scan, and altogether 3854 persons attended. Among these, a VFA, also called lateral vertebral assessment (LVA), was performed in a randomly selected group of 2894 persons. Seven blurred VFA scans had to be excluded, leaving 2887 persons, 1206 men and 1681 women, with clearly measurable VFA scans and total hip measurements. Among the 2887 persons with VFA scans, we obtained the following numbers according to each vertebral level: $\mathrm{T} 4=2350$, T5 $=2743, \mathrm{~T} 6=2845$, $\mathrm{T} 7=2863, \mathrm{~T} 8=2875, \mathrm{~T} 9=2878, \mathrm{~T} 10=2885, \mathrm{~T} 11-\mathrm{L} 3=2887$, $\mathrm{L} 4=2848$.

\section{Ascertainment of vertebral fracture}

Vertebral fracture was ascertained by the VFA of the GE Lunar Prodigy, Lunar Corporation, Madison, WI, USA, version 12.20. Vertebral morphometry is a quantitative method developed for identification of osteoporotic vertebral fractures based on the measurement of vertebral heights, identifying the anterior, middle, and posterior heights of each vertebra. Depending on their relative relations according to a given reference, the software identifies three types of fractures: wedge, biconcave, and compression, according to three degrees of severity, ranging from mild through moderate to severe [25]. Although some authors suggest that spinal radiograph is the gold standard for the diagnosis of vertebral fractures $[13,26]$, the morphometric method is recognized as being easy, precise and using low radiation exposure $[25,27,28]$, with high precision in measuring moderate and severe deformities [13]. In our dataset, only $1 \%$ of the deformities were identified as being mild, the majority were either moderate or severe [23]. All our scans were taken according to the standard set by GE Lunar Prodigy, and specially trained technicians did the scanning according to the standardized protocol. One of the technicians (the first author) performed the quality assessment of the total material afterwards. For precision analysis of the VFA, a random sample of 50 participants was re-analyzed by the same technician. The mean intra-class correlation coefficient was 0.84 for average height of the vertebrae [23].

\section{Bone mineral density}

BMD expressed as $\mathrm{g} / \mathrm{cm}^{2}$ was measured at the total hip and femoral neck by DXA, using the same densitometer as for the VFA (GE Lunar Prodigy). Daily phantom measurements were performed throughout the survey. Three technicians did the scanning according to a standardized protocol, and one of them performed the quality assessment of the total material afterwards. The short term in vivo precision error was 1.2 and $1.7 \%$ for total hip and femoral neck measurements, respectively [29]. For the main analyses of this study, we have included BMD measurement of the total hip, where 2738 valid 
measurements were available (either left or right hip). Based on the Lunar reference, 102 persons (3.5\%) had a $\mathrm{T}$-score $\leq-2.5$ (osteoporosis) and 789 persons (27\%) had a $\mathrm{T}$ score between -2.5 and -1.0 (osteopenia).

\section{Questionnaire}

Data on lifestyle variables were collected through questionnaires in both phases of the study. The questionnaires obtained information, among other, on smoking habits, physical activity, self-perceived health, and education. Smoking status was classified into three categories, namely: present, former, and never. These were further grouped into two categories: former and never smokers were categorized as "not smoking" and smokers as "smoking". The question on leisure time physical activity level during the last year had four alternatives from sedentary (mostly tranquil activities), moderate (lightly active at least four hours a week), active (vigorously active at least four hours a week) and highly active (exercising regularly several times a week). The sedentary and moderate active were categorized into one "low active group", and the active and highly active into one "high active" group. Five levels of self-perceived health (very good, good, neither good nor bad, bad, and very bad) were categorized into two, good (very good and good) and poor. Five levels of education were categorized into three levels: 1) primary school only (i.e. seven years), 2) up to four years more than primary school, and 3) more than four years after primary school.

\section{Data analysis}

Each individual was classified as having a vertebral fracture if there was a presence of at least one fracture as described in the "Ascertainment of vertebral fracture" section. The association between sex and vertebral fracture risk was assessed by Chi-square statistics. Univariate analyses (Chi-square statistics or Independent sample T-tests) were used to examine the association between baseline characteristics and vertebral fracture risk in women and men. Logistic regression was used to assess the association between each risk factors and vertebral fracture risk in women and men separately, adjusting for age. Odds ratio (OR) of fracture (and 95\% confidence interval (CI)) was estimated per standard deviation (SD) of continuous risk factors (e.g., BMD, body mass index (BMI)). Multivariable logistic regression analysis was used to assess the association between each significant or combined risk factors and vertebral fracture risk. Testing for interaction was done by including the product of sex and BMD and sex and age in the model. The final and most optimal model was found using backward selection procedures. In order to assess the impact of risk factors on vertebral fracture, we estimated the population attributable risk fraction (PAR) for combined risk factors in the "final" multivariable model, for women and men separately. In this study context, PAR represents the proportion of vertebral fractures that can be attributed to a risk factor, if there is a causal relationship between the risk factor and fracture [30]. However, because vertebral fracture is associated with multiple risk factors, stratified models were used to estimate the fracture risk in four categories of exposure and the heuristic approach described by Hanley, J.A. [31] was used to calculate the PAR. The formula used to calculate the attributable risk (AR) (actually called attributable fraction) was the following: $A R=\frac{\left(R R_{i}-1\right) \times P c t_{i}}{1+\sum_{i}^{n}\left(R R_{i}-1\right) \times P c t_{i}}$ (where (n) is the total number of the categories, and (i) takes value of each category risk (RR) and percentage (Pct)). All statistical analyses were performed with the SPSS statistical package (versions 19).

\section{Results}

The study cohort included 2887 individuals (1206 men and 1681 women) aged between 38 and 87 years, with the majority being post-menopausal (women) or aged $50+$ years.

Overall, approximately $64 \%$ of men and $61 \%$ of women reported good health status, with a majority (more than $78 \%$ ) in the sedentary or moderately physical activity group.

Vertebral fracture was found in 166 (13.8\%) men and $199(11.8 \%)$ women $(p=0.07)$. Baseline characteristics of participants stratified by fracture status and sex are shown in Table 1. Men and women with a vertebral fracture were on average older than those without and had lower total hip BMD. Among women, those with a fracture also had lower levels of education and poor overall self-reported health status compared to those without a fracture in addition to lower weight and stature. The results did not change when we included only participants above 50 years of age in analyses.

In either sex, age was significantly associated with the prevalence of vertebral fracture $(\mathrm{p}<0.001)$ (Figure 1). When data were combined and analyzed in a bivariate logistic regression model (Table 2), the risk of vertebral fracture increased with advancing age, OR 1.43; 95\% CI: 1.31 to 1.56 in women and OR $1.28 ; 95 \% \mathrm{CI}: 1.17$ to 1.40 in men, per 5-year increase. Decreasing total hip BMD, increased body weight and higher stature were each associated with reduced vertebral fracture risk, but after adjusting for age, only BMD was associated with vertebral fracture risk in men (OR 1.40; 95\% CI: 1.18 to 1.67 per $-0.14 \mathrm{~g} / \mathrm{cm}^{2}$ decrease), and in women only BMD (OR 1.60; $95 \%$ CI: 1.34 to 1.90 per $-0.13 \mathrm{~g} / \mathrm{cm}^{2}$ decrease) and weight (OR 0.93; 95\% CI: 0.88 to 0.99 per $5 \mathrm{~kg}$ increase) (Table 2) 
Table 1 Descriptive statistics by gender and morphometric vertebral fracture, the Tromsø Study 2007-08

\begin{tabular}{lccc}
\hline Gender and factor & No Fracture & Vertebral fracture & P-value \\
\hline Women $(\mathbf{N})$ & $\mathbf{1 4 8 2}$ & $\mathbf{1 9 9}$ & \\
\hline Age $($ years) & $64.7(9.3)$ & $70.5(8.6)$ & $<0.0001$ \\
\hline Weight $(\mathrm{kg})$ & $71.1(12.5)$ & $68.4(12.7)$ & 0.005 \\
\hline Height $(\mathrm{cm})$ & $162.5(6.3)$ & $160.4(7.1)$ & $<0.0001$ \\
\hline BMl $\left(\mathrm{kg} / \mathrm{m}^{2}\right)$ & $26.9(4.6)$ & $26.6(4.5)$ & 0.297 \\
\hline Total hip BMD $\left(\mathrm{g} / \mathrm{m}^{2}\right)$ & $0.91(0.13)$ & $0.83(0.11)$ & $<0.001$ \\
\hline Education & & & 0.009 \\
\hline Primary school $(\mathrm{n} ; \%)$ & $627(43.0)$ & $106(54.4)$ & \\
\hline O-level & $375(25.7)$ & $44(22.6)$ & \\
\hline More than O-level & $456(31.3)$ & $45(23.1)$ & \\
\hline
\end{tabular}

Physical activity 0.796

\begin{tabular}{lrr}
\hline High active $(n ; \%)$ & $144(11.2)$ & $18(10.5)$ \\
\hline Low active & $1143(88.8)$ & $153(89.5)$ \\
\hline
\end{tabular}

\begin{tabular}{lccc}
\hline Smoking status & & & 0.750 \\
\hline Daily smokers $(n ; \%)$ & $265(18)$ & $37(19)$ & \\
\hline Non smoking & $1189(82)$ & $156(81)$ & \\
\hline
\end{tabular}

\begin{tabular}{llcc}
\hline Health status & & & 0.029 \\
\hline Good $(n ; \%)$ & $905(61.9)$ & $106(53.8)$ & \\
\hline Poor & $557(38.1)$ & $91(46.2)$ &
\end{tabular}

\begin{tabular}{lcc}
\hline Poor & $557(38.1)$ & $91(46.2)$ \\
\hline Men (N) & $\mathbf{1 0 4 0}$ & $\mathbf{1 6 6}$
\end{tabular}

\begin{tabular}{lccc}
\hline Age (years) & $64.8(9.3)$ & $69.0(9.2)$ & $<0.0001$ \\
\hline Weight $(\mathrm{kg})$ & $84.5(12.3)$ & $82.8(11.5)$ & 0.078 \\
\hline Height $(\mathrm{cm})$ & $175.5(6.5)$ & $174.4(6.7)$ & 0.062 \\
\hline BMI $\left(\mathrm{kg} / \mathrm{m}^{2}\right)$ & $27.4(3.5)$ & $27.2(3.4)$ & 0.457 \\
\hline Total hip BMD $\left(\mathrm{g} / \mathrm{m}^{2}\right)$ & $1.03(0.14)$ & $0.98(0.15)$ & $<0.001$
\end{tabular}

\begin{tabular}{ll}
\hline Education & 0.147
\end{tabular}

\begin{tabular}{lll}
\hline Primary school $(n ; \%)$ & $324(31.9)$ & $54(33.5)$ \\
\hline O-level & $287(28.2)$ & $55(34.2)$ \\
\hline More than O-level & $405(39.9)$ & $52(32.3)$ \\
\hline
\end{tabular}

\begin{tabular}{ll}
\hline Physical activity & 0.577 \\
\hline
\end{tabular}

\begin{tabular}{llr}
\hline High active $(n ; \%)$ & $213(22.6)$ & $31(20.5)$ \\
\hline Low active & $731(77.4)$ & $120(79.5)$ \\
\hline
\end{tabular}

\begin{tabular}{llll}
\hline Smoking status & & & 0.988 \\
\hline Daily smokers $(\mathrm{n} ; \%)$ & $159(15.5)$ & $25(15.5)$ & \\
\hline Non smoking & $868(84.5)$ & $136(84.5)$
\end{tabular}

\begin{tabular}{llll} 
Non smoking & $868(84.5)$ & $136(84.5)$ & \\
\hline Health status & & 0.574 \\
\hline
\end{tabular}

\begin{tabular}{lll}
\hline Good $(n ; \%)$ & $662(64.1)$ & $102(61.8)$ \\
\hline Poor & $371(35.9)$ & $63(38.2)$ \\
\hline
\end{tabular}

*P-values refer to univariate analyses.

Because sex was not associated with the prevalence of vertebral fractures in any age group $(\mathrm{p}>0.12)$ (Figure 1), we wanted to explore the association between sex and vertebral fracture risk. BMD was inversely related to the prevalence of vertebral fracture in both sexes $(\mathrm{p}<0.001)$ (Figure 2). After adjusting for age and BMD, the odds of

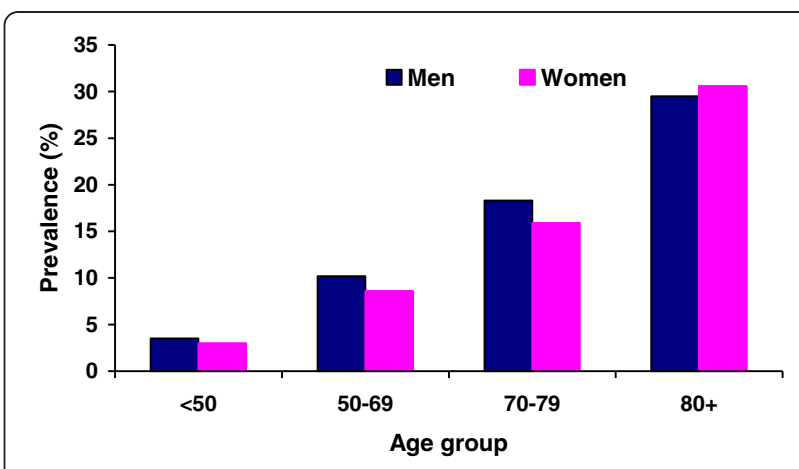

Figure 1 The association between age and the prevalence of morphometric vertebral fracture in women and men,

Tromsø Study 2007-08. Age was significantly associated with the prevalence of vertebral fracture in women and men $(p<0.001)$.

vertebral fracture in men was 1.87 -fold ( $95 \%$ CI 1.4 to 2.5) higher than in women. Testing for interaction between the variables showed that there was no interaction between sex and age $(p=0.08)$, but a significant interaction between sex and BMD $(p=0.005)$. According to the WHO definition [32], $1.5 \%$ of all men and $6 \%$ of all women had osteoporosis (T-score $\leq-2.5$ at the total hip). Categorizing BMD into T-scores, men had greater risk of vertebral fracture than women in the normal and normal + groups $(\mathrm{T}$ scores $>-1.5)(\mathrm{p}<0.012)$ and in the osteoporosis group $(\mathrm{p}=0.011)$, but the numbers were low. We therefore categorized the BMD levels into quartiles, kept the lowest quartile of less than $0.85 \mathrm{~g} / \mathrm{cm}^{2}$ as one group, and the rest as another. With this stratification, at BMD levels higher than $0.85 \mathrm{~g} / \mathrm{cm}^{2}$, men had a greater risk of fracture than women (OR 1.52; 95\% CI 1.14-2.04), after adjusting for age.

A multivariable logistic regression model was conducted to search for independent risk factors for each sex separately, and the results are shown in Table 3. For both women and men the "final" and most optimal model for predicting fracture risk included age and total hip BMD. For a given age group, the risk of fracture increased as BMD decreased. Conversely, for a given BMD category, the prevalence of fracture increased with advancing age. Attributable risk analysis (Table 4) indicated that in women $45.9 \%$ and in men $33.4 \%$ of all vertebral fractures cases were attributable to advancing age (i.e. more than 70 years) and lower total hip BMD (i.e. less than $0.85 \mathrm{~g} / \mathrm{cm}^{2}$ ).

\section{Discussion}

In line with other studies [21,22,33], we found that advancing age and lower BMD at the total hip were independent determinants of vertebral fracture risk, whereas all other background- and lifestyle variables did not contribute statistically in the final model. The estimated 
Table 2 The association between risk factors and morphometric vertebral fracture in bivariate analysis (logistic regression)

\begin{tabular}{|c|c|c|c|}
\hline \multirow[t]{2}{*}{ Risk factor } & \multirow{2}{*}{$\begin{array}{l}\text { Unit of } \\
\text { comparison }\end{array}$} & \multirow{2}{*}{$\frac{\mathrm{OR} \text { and } 95 \% \mathrm{Cl}}{\text { Women }}$} & \multirow{2}{*}{$\frac{\mathrm{OR} \text { and } 95 \% \mathrm{Cl}}{\text { Men }}$} \\
\hline & & & \\
\hline Age & +5 years & $1.43(1.31-1.56)$ & $1.28(1.17-1.40)$ \\
\hline Total hip BMD & $-0.13 /-0.14 \mathrm{~g} / \mathrm{cm}^{2^{*}}$ & $1.60(1.34-1.90)$ & $1.40(1.18-1.67)$ \\
\hline Weight & $+5 \mathrm{~kg}$ & $0.93(0.88-0.99)$ & $0.99(0.92-1.06)$ \\
\hline Height & $+5 \mathrm{~cm}$ & $0.89(0.79-1.01)$ & $0.97(0.85-1.11)$ \\
\hline $\mathrm{BMI}$ & $+4 \mathrm{~kg} / \mathrm{m}^{2}$ & $0.88(0.74-1.04)$ & $0.99(0.78-1.27)$ \\
\hline Health status & Good vs Poor & $0.87(0.64-1.19)$ & $0.98(0.70-1.38)$ \\
\hline Physical activity & High vs Low & $1.11(0.65-1.89)$ & $0.92(0.60-1.41)$ \\
\hline Smoking status & Yes vs No & $0.77(0.52-1.14)$ & $0.88(0.55-1.40)$ \\
\hline
\end{tabular}

population attributable risk fraction for these two factors combined was $45.9 \%$ in women and $33.4 \%$ in men.

At the highest BMD levels, the risk of vertebral fracture at given age was greater in men than in women. Few population-based studies have included vertebral fracture assessment in both women and men. It is therefore difficult to compare the present sex-related vertebral fracture risk. There has been some controversy in the literature about whether there is a higher risk of vertebral fractures in women than in men. Our finding of non-significant difference in vertebral fracture risk between men and women (before adjustment of age and BMD) is not consistent with a previous review which suggested that the incidence of vertebral fractures in men is about one third to one half of that in women [34], but of course, our estimates are based on prevalent vertebral fractures. However, our results are in line with findings from the Dubbo Osteoporosis Epidemiological Study [35] where the prevalence of vertebral deformities was higher in men than in women. In that study the higher prevalence in men was observed regardless of

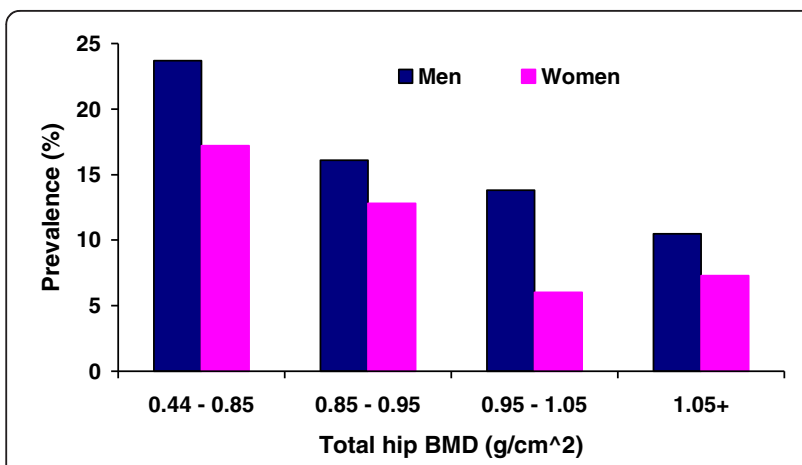

Figure 2 The association between BMD and the prevalence of morphometric vertebral fracture in women and men, Tromsø Study $2007-08$. diagnostic criteria, suggesting, as in our study, that vertebral fractures may be overlooked in men.

Several other studies report, similar to the present study, that low BMD measured at the femoral sites are associated with prevalent radiographic vertebral fractures $[21,22,28]$. We have not seen other studies comparing sex difference at normal and normal + levels (not osteoporosis nor osteopenia). The higher prevalence of vertebral deformities at these BMD levels in men indicate, as also suggested by others [16], that these deformities could be of other origin than osteoporosis, possibly mechanic or due to childhood diseases [34] and should be explored in follow up studies. Studies defining the proportion of fractures attributable to trauma in childhood and young adulthood are lacking [34]. As Seeman et al. claims, if these youth fractures do make a contribution to the numbers of elderly men with fractures, this will exaggerate the prevalence of vertebral fractures and by that mask a sex difference in the prevalence of osteoporotic vertebral fractures [34], something that should be examined in follow-up studies. The finding from our study indicating that at a given age and given BMD level the OR for having a vertebral fracture is higher in men than in women, somehow corresponds to how the risk of hip fractures seems to be similar in men and women for any given BMD [16,32,36,37]. Although an unknown proportion of the vertebral fractures in men may be of mechanic origin, our study highlights the importance of osteoporosis and vertebral fracture risk in men, and that vertebral fractures should definitely not be considered a women health problem only.

The present findings should be viewed within the context of strengths and potential limitations. The Tromsø Study is a population-based, longitudinal study with a high participation rate. The present study is a crosssectional survey within the framework of the Troms $\varnothing$ Study, where vertebral morphometry was done for the first time. Because of its cross-sectional design, causal inference cannot be drawn from the findings and the results will need confirmation within a longitudinal design. For logistic reasons, we did not perform quality control using $\mathrm{x}$-ray technology. It is, however, reported that DXA scans are more precise in measuring moderate and severe than mild deformities [13], and $99 \%$ of the identified deformities in our data set were either moderate or severe. The intra-class correlation coefficient for determination of average height of the vertebra was good. Ideally, we should have compared determination of fracture severity in the sample. This was, however, difficult to attain, since determination is done electronically by the software, based on identified vertebral heights. Despite of random selection in the Tromsø Study, the morphometry group was younger with a slightly lower proportion of women compared to the group not 
Table 3 Risk factors for morphometric vertebral fracture in multivariable analysis (This analysis was based on 2738 subjects, not 2887 )

\begin{tabular}{|c|c|c|c|}
\hline \multirow[t]{2}{*}{ Risk factor } & \multirow{2}{*}{$\begin{array}{l}\text { Unit of } \\
\text { comparison }\end{array}$} & \multirow{2}{*}{$\frac{\mathrm{OR} \text { and } 95 \% \mathrm{Cl}}{\text { Women }}$} & \multirow{2}{*}{$\frac{\mathrm{OR} \text { and } 95 \% \mathrm{Cl}}{\text { Men }}$} \\
\hline & & & \\
\hline Age & +5 years & $1.32(1.19-1.45)$ & $1.21(1.10-1.33)$ \\
\hline
\end{tabular}

Total hip BMD $-0.13 /-0.14 \mathrm{~g} / \mathrm{cm}^{2 *} 1.60(1.34-1.90) \quad 1.40(1.18-1.67)$

Note: All OR: $p<0.001{ }^{*}-1$ SD which was $-0.13 \mathrm{~g} / \mathrm{cm}^{2}$ in women and $-0.14 \mathrm{~g} / \mathrm{cm}^{2}$ in men.

selected to VFA. However, when we compare the morphometry group with the phase 2 participants of the Tromsø VI survey, whom to our best knowledge should be a representative sample [24], the morphometry sample of women and men was slightly older (3 years) with lower height $(2 \mathrm{~cm})$, but did not differ significantly in any other way. Despite high rates of hip- and forearm fractures in Norway, the prevalence of vertebral fractures in this population was comparable to reports from others [38-40]. Although we should be careful drawing firm conclusions from our prevalence estimates, we still feel comfortable to compare between women and men, especially in age stratified analyses. It is a major limitation to our study that we lack information of important risk factors included in FRAX [20], especially the history of vertebral fractures [21,33]. Although BMI [41] and smoking [42] are considered to be independent predictors of fracture risk, they did not contribute to the final model. The predictive value of physical activity, self-perceived health, and education to fracture risk is uncertain [43] and did not affect the results although the self-reported nature and our dichotomization of the variables may have precluded possible associations.

Table 4 Determination of attributable risk (heuristic methods)

\begin{tabular}{lccccc}
\hline Age & BMD & N & Percent & RR & PAR \\
\hline Women & & & & & \\
\hline$<70$ & $0.85+$ & 781 & 49.7 & 1.0 & \\
\hline <0.85 & 296 & 18.8 & 1.72 & 7.4 \\
\hline $70+$ & $0.85+$ & 227 & 14.4 & 2.01 & 7.9 \\
\hline All & $<0.85$ & 267 & 17.0 & 4.33 & 30.6 \\
\hline Men & All & 1571 & 100 & & $\mathbf{4 5 . 9}$ \\
\hline$<70$ & $0.85+$ & 692 & 59.3 & 1.0 & \\
\hline & $<0.85$ & 49 & 4.2 & 1.79 & 2.2 \\
\hline $70+$ & $0.85+$ & 357 & 30.6 & 2.00 & 20.4 \\
\hline & $<0.85$ & 69 & 5.9 & 3.75 & 10.8 \\
\hline All & All & 1167 & 100 & & $\mathbf{3 3 . 4}$ \\
\hline Rerark Approximaly & & & & & \\
\hline
\end{tabular}

Remark: Approximately $46 \%$ of all vertebral fracture cases in women were attributable to old age and low BMD, with the latter - low BMD - $(31 \%)$ having more pronounced effect than the former. In men, $33 \%$ of the fracture cases were attributable to old age and low BMD, with the former - old age - $(20 \%)$ having more effect than the latter.
However, this study confirms that age and BMD are important predictors of vertebral fractures in women and men $[21,22]$.

\section{Conclusion}

Advancing age and declining BMD are independent determinants of vertebral fracture risk in women and men, but accounting for less than half of the total risk. The predictive value of prevalent vertebral fractures on subsequent vertebral fractures and other types of fractures should be explored in longitudinal studies.

\section{Competing interests}

The authors declare that they have no competing interests.

\section{Authors' contributions}

Contributions of the authors to the manuscript included Study concept and design: NE, SW, AJS; Acquisition of data: NE, SW, NDN, LAA; Analyses and interpretation of data: SW, NE, LAA, AJS, JC, JAE; Statistical analyses: SW, NE, LAA, TN; Critical revision of the manuscript: SW, LAA, AJS, JC, NDN, TN, JAE, NE. All authors read and approved the final manuscript.

\section{Acknowledgements}

The project was funded by grants from The Northern Norwegian Health Authorities.

We are thankful for the support provided by the Tromsø Study Organization.

\section{Author details}

${ }^{1}$ Department of Community Medicine, Faculty of Health Sciences, University of Tromsø, Tromsø 9037, Norway. ${ }^{2}$ Garvan Institute of Medical Research, University of New South Wales, Sydney, Australia. ${ }^{3}$ Department of Health and Care Sciences, University of Tromsø, 9037, Tromsø, Norway. ${ }^{4}$ St. Vincent's Hospital, Sydney, Australia. ${ }^{5}$ Norwegian Institute of Public Health, Oslo, Norway.

Received: 6 February 2012 Accepted: 27 August 2012

Published: 31 August 2012

\section{References}

1. Harvey N, Dennison E, Cooper C: Osteoporosis: impact on health and economics. Nat Rev Rheumatol 2010, 6(2):99-105.

2. Bliuc D, Nguyen ND, Milch VE, Nguyen TV, Eisman JA, Center JR: Mortality risk associated with low-trauma osteoporotic fracture and subsequent fracture in men and women. JAMA 2009, 301(5):513-521.

3. Ahmed LA, Schirmer $H$, Bjornerem A, Emaus $N$, Jorgensen L, Stormer J, Joakimsen RM: The gender- and age-specific 10-year and lifetime absolute fracture risk in Tromso, Norway. Eur J Epidemiol 2009, 24(8):441-448.

4. Johnell O, Kanis J: An estimate of the worldwide prevalence and disability associated with osteoporotic fractures. Osteoporos Int 2006, 17(12):1726-1733.

5. Francis R, Aspray T, Hide G, Sutcliffe A, Wilkinson P: Back pain in osteoporotic vertebral fractures. Osteoporos Int 2008, 19(7):895-903.

6. El Maghraoui A, Mounach A, Rezqi A, Achemlal L, Bezza A, Ghozlani I: Vertebral fracture assessment in asymptomatic men and its impact on management. Bone 2012, 50(4):853-857.

7. Center JR, Bliuc D, Nguyen TV, Eisman JA: Risk of subsequent fracture after low-trauma fracture in men and women. JAMA 2007, 297(4):387-394.

8. Lindsay R, Silverman SL, Cooper C, Hanley DA, Barton I, Broy SB, Licata A, Benhamou L, Geusens P, Flowers $K$, et al: Risk of new vertebral fracture in the year following a fracture. JAMA 2001, 285(3):320-323.

9. Naves M, Díaz-López JB, Gómez C, Rodríquez-Rebollar A, Rodríguez-García $M$, Cannata-Andía JB: The effect of vertebral fracture as a risk factor for osteoporotic fracture and mortality in a Spanish population. Osteoporos Int 2003, 14(6):520-524

10. Briggs A, Greig A, Wark J: The vertebral fracture cascade in osteoporosis: a review of aetiopathogenesis. Osteoporos Int 2007, 18(5):575-584. 
11. Roux C, Fechtenbaum J, Kolta S, Briot K, Girard M: Mild prevalent and incident vertebral fractures are risk factors for new fractures. Osteoporos Int 2007, 18(12):1617-1624

12. Melton $\amalg$ III, Atkinson EJ, Cooper C, O'Fallon WM, Riggs BL: Vertebral fractures predict subsequent fractures. Osteoporos Int 1999, 10(3):214-221.

13. Middleton E, Gardiner E, Steel S: Which women should be selected for vertebral fracture assessment? comparing different methods of targeting VFA. Calcified Tissue Int 2009, 85(3):203-210.

14. Puisto $V$, Heliövaara $M$, Impivaara $O$, Jalanko $T$, Kröger $H$, Knekt $P$, Aromaa $A$, Rissanen $\mathrm{H}$, Helenius I: Severity of vertebral fracture and risk of hip fracture: a nested case-control study. Osteoporos Int 2011, 22(1):63-68.

15. Pongchaiyakul C, Nguyen ND, Jones G, Center JR, Eisman JA, Nguyen TV: Asymptomatic vertebral deformity as a major risk factor for subsequent fractures and mortality: a long-term prospective study. J Bone and Mineral Res 2005, 20(8):1349-1355.

16. Kanis JA, Johnell O, Oden A, De Laet C, Mellstrom D: Epidemiology of osteoporosis and fracture in men. Calcified Tissue Int 2004, 75(2):90-99.

17. Lewiecki E: Bone densitometry and vertebral fracture assessment. Current Osteoporosis Rep 2010, 8(3):123-130.

18. Lofthus CM, Osnes EK, Falch JA, Kaastad TS, Kristiansen IS, Nordsletten L, Stensvold I, Meyer HE: Epidemiology of hip fractures in Oslo, Norway. Bone 2001, 29(5):413-418.

19. Lofthus C, Frihagen F, Meyer H, Nordsletten L, Melhuus K, Falch J: Epidemiology of distal forearm fractures in Oslo, Norway. Osteoporos Int 2008, 19(6):781-786.

20. Kanis J, Hans D, Cooper C, Baim S, Bilezikian J, Binkley N, Cauley J, Compston J, Dawson-Hughes B, El-Hajj Fuleihan G, et al: Interpretation and use of FRAX in clinical practice. Osteoporosis Int 2011, 22(9):2395-2411.

21. Shin C, Kim M, Shim S, Kim J, Yu S, Koo B, Cho H, Choi H, Cho S, Kim S, et al: The prevalence and risk factors of vertebral fractures in Korea. Journal of Bone and Mineral Metabolism 2012, 30(2):183-192.

22. Fujiwara S, Hamaya E, Goto W, Masunari N, Furukawa K, Fukunaga M, Nakamura T, Miyauchi A, Chen P: Vertebral fracture status and the World Health Organization risk factors for predicting osteoporotic fracture risk in Japan. Bone 2011, 49(3):520-525.

23. Waterloo S, Ahmed L, Center J, Eisman J, Morseth B, Nguyen N, Nguyen T, Sogaard A, Emaus N: Prevalence of vertebral fractures in women and men in the population based Tromso study. BMC Musculoskelet Disord 2012, 13(1):3.

24. Jacobsen BK, Eggen AE, Mathiesen EB, Wilsgaard T, Njølstad I: Cohort profile: the Tromsø study. Int J Epidemiol 2011,

25. El Maghraoui A, Roux C: DXA scanning in clinical practice. QJM 2008, 101(8):605-617.

26. Diacinti D, Guglielmi G: Vertebral morphometry. Radiol Clin North Am 2010, 48(3):561-575

27. Grigoryan M, Guermazi A, Roemer F, Delmas P, Genant H: Recognizing and reporting osteoporotic vertebral fractures. Eur Spine J 2003, 12:S104-S112.

28. Ensrud KE, Schousboe JT: Vertebral Fractures. N Engl J Med 2011, 364(17):1634-1642

29. Omsland TK, Emaus N, Gjesdal CG, Falch JA, Tell GS, Forsen L, Berntsen GK, Meyer HE: In vivo and in vitro comparison of densitometers in the NOREPOS study. J Clin Densitom 2008, 11(2):276-282

30. Woodward M: Epidemiology study design and data analysis. 2nd edition. London: Chapman and Hall; 2005.

31. Hanley JA: A heuristic approach to the formulas for population attributable fraction. J Epidemiol Community Health 2001, 55(7):508-514

32. Kanis JA: Diagnosis of osteoporosis and assessment of fracture risk. Lancet 2002, 359(9321):1929-1936.

33. Donaldson MG, Palermo L, Schousboe JT, Ensrud KE, Hochberg MC, Cummings SR: FRAX and risk of vertebral fractures: the fracture intervention trial. Journal of bone and mineral research: the official journal of the American Society for Bone and Mineral Research 2009, 24(11):1793-1799.

34. Seeman E, Bianchi G, Khosla S, Kanis J, Orwoll E: Bone fragility in men where are we? Osteoporos Int 2006, 17(11):1577-1583.

35. Jones G: Prevalent vertebral deformities: relationship to bone mineral density and spinal osteophytosis in elderly men and women. Osteoporos Int 1996, 6(3):233-239.

36. Orwoll E: Assessing bone density in men. J Bone Miner Res 2000, 15(10):1867-1870.

37. Melton $\sqcup \mathrm{III}$, Orwoll ES, Wasnich RD: Does bone density predict fractures comparably in men and women? Osteoporos Int 2001, 12(9):707-709.
38. Pasco J, Henry M, Korn S, Nicholson G, Kotowicz M: Morphometric vertebral fractures of the lower thoracic and lumbar spine, physical function and quality of life in men. Osteoporos Int 2009, 20(5):787-792.

39. Clark P, Cons-Molina F, Deleze M, Talavera J, Palermo L, Cummings S: The prevalence of radiographic vertebral fractures in Mexican men. Osteoporos Int 2010, 21(9):1523-1528.

40. O'Neill TW, Felsenberg D, Varlow J, Cooper C, Kanis JA, Silman AJ: The prevalence of vertebral deformity in European men and women: the European vertebral osteoporosis study. J Bone Miner Res 1996, 11(7):1010-1018

41. De Laet C, Kanis JA, Oden A, Johanson H, Johnell O, Delmas P, Eisman JA, Kroger H, Fujiwara S, Garnero P, et al: Body mass index as a predictor of fracture risk: a meta-analysis. Osteoporosis international: a journal established as result of cooperation between the European Foundation for Osteoporosis and the National Osteoporosis Foundation of the USA 2005, 16(11):1330-1338

42. Dimai HP, Chandran M: Official positions for $\operatorname{FRAX(R)~clinical~regarding~}$ smoking from joint official positions development conference of the international society for clinical densitometry and international osteoporosis foundation on $\operatorname{FRAX(R).~Journal~of~clinical~densitometry:~the~}$ official journal of the International Society for Clinical Densitometry 2011, 14(3):190-193.

43. Kanis JA, Hans D, Cooper C, Baim S, Bilezikian JP, Binkley N, Cauley JA, Compston JE, Dawson-Hughes B, El-Hajj Fuleihan G, et al: Interpretation and use of FRAX in clinical practice. Osteoporosis international: a journal established as result of cooperation between the European Foundation for Osteoporosis and the National Osteoporosis Foundation of the USA 2011, 22(9):2395-2411.

doi:10.1186/1471-2474-13-163

Cite this article as: Waterloo et al:: Important risk factors and attributable risk of vertebral fractures in the population-based Troms $\varnothing$ study. BMC Musculoskeletal Disorders 2012 13:163.

\section{Submit your next manuscript to BioMed Central and take full advantage of:}

- Convenient online submission

- Thorough peer review

- No space constraints or color figure charges

- Immediate publication on acceptance

- Inclusion in PubMed, CAS, Scopus and Google Scholar

- Research which is freely available for redistribution

Submit your manuscript at www.biomedcentral.com/submit
C Biomed Central 